\title{
An Economic Theory of Leadership Turnover*
}

\author{
M. Gallego $\quad$ C. Pitchik ${ }^{\ddagger}$
}

June 11, 2003

\begin{abstract}
In an infinite horizon stochastic model, a coup not only disciplines a dictator's policy towards a group of "kingmakers" but also enables a kingmaker to become dictator. Greater competition for the dictator's position, a lower impact of the dictator's policy on the kingmakers, or lower risks of staging a coup raises the benefit of a coup relative to its opportunity cost and so raises the probability of a coup. Since periodic shocks affect the efficacy of the dictator's policy, a bad enough shock makes it too costly for even talented dictators to avert a coup. More talented dictators are able to survive more negative shocks, so the worst shock in a dictator's reign is informative about the probability of a coup. Conditional on the worst shock, the probability of a coup is independent of a dictator's duration in office. The unconditional probability declines with duration.
\end{abstract}

Keywords: coup d'état, kingmakers, dictator, hazard rate, dynamic, stochastic games, infinite horizon.

JEL Classification: C73, D72, P16.

*We thank Gordon Anderson, Jeffrey Banks, Albert Berry, Eugene Choo, Nancy Gallini, Edward Green, Arthur Hosios, Yehuda Kotowitz, David Laitin, Angelo Melino, Peter Dungan, Martin J. Osborne, Mike Peters, Anatol Rapoport, Aloysius Siow, Nicolas van de Walle, Adonis Yatchew, Myrna Wooders and two referees for helpful comments and discussions. We are grateful to Arthur Hosios and Martin J. Osborne for reading an earlier draft and making many valuable comments and suggestions. Pitchik gratefully acknowledges financial support from the Social Sciences and Humanities Research Council of Canada.

${ }^{\dagger}$ Dept. of Economics, Wilfrid Laurier University, Internet: mgallego@wlu.ca

†Please send correspondence to Prof. C. Pitchik, Dept. of Economics, University of Toronto, 150 St. George St., Toronto, M5S 3G7, Canada, Internet: Pitchik@chass.utoronto.ca 


\section{Introduction}

A majority of the world's fallen political leaders are not defeated in popular elections $^{1}$. The attention devoted to modeling coups d'état and other non-democratic processes has, however, been small compared with that devoted to "democratic" electoral processes.

We study an infinite-horizon model in which the actions of a leader ("dictator") are disciplined by the threat that a finite group of "kingmakers" may displace the leader by staging a coup. In each period, the reigning dictator makes an investment that affects the kingmakers. Our model is general, but we think of the kingmakers as entrepreneurs engaged in the export trade; the dictator's investment increases the profitability of this trade. The efficacy of the dictator's investment in any given period depends on the realization of a commonly-observed random variable in that period. We think of this random variable as the export price; the higher its value, the higher are the kingmakers' profits. In any period, the kingmakers may stage a coup. The outcome of a coup is probabilistic. With probability $q$ a new dictator is selected from the set of kingmakers, in which case this set is replenished by selecting a new kingmaker from an infinite set of potential kingmakers. With probability $1-q$ a new dictator is selected from the set of potential kingmakers, in which case each kingmaker ceases to be kingmaker with positive probability. Under this assumption, a coup is risky for a kingmaker-it may result in the kingmaker's losing access to the effects of the dictator's investment and losing the ability to stage a coup. Kingmakers differ in their ability as dictator; a kingmaker's ability is private information, known only to that kingmaker, and only after the kingmaker becomes the dictator.

We show that the resulting extensive game has a unique symmetric Markov sequential Nash equilibrium (MSE), which has a simple and intuitive structure. For any value of the export price $p$, the kingmakers stage a coup whenever the

\footnotetext{
${ }^{1}$ Of 1,028 leaders who reached high office between 1945 and 1976, 859 fell from power; of these 859 , only $5 \%$ were defeated at election. By contrast, $20 \%$ of leadership turnovers were due to irregular pressures such as a coup. (Blondel, 1980, p.198, Table 1)
} 
dictator's investment is below the coup-averting investment which decreases in the export price. If the export price is lower than some cutoff, the dictator does not invest at all (and induces a coup), and if the export price is above the cutoff the dictator makes the coup-averting investment (and averts a coup).

The kingmakers' equilibrium strategy is based on a comparison of the benefit and opportunity cost of staging a coup. The benefit depends only on future values and is thus independent of the current investment and export price. The opportunity cost, however, increases in both these variables. Thus the coupaverting investment decreases in $p$. When $p$ is low enough, the investment required to avert a coup is too high to be worthwhile for the dictator, who is consequently overthrown. (This result holds even if all players have the same ability as dictator.)

The kingmakers' desire to become dictator drives the demand for coups. Our model predicts that a coup is more likely the greater the competition for the dictator's position (i.e. the larger the number of kingmakers), the smaller the impact of the dictator's investment on the kingmakers' profits, and the lower the risk of staging a coup (i.e. the lower the probability that a kingmaker loses access to power when a coup is staged) since, in equilibrium, each of these parameter modifications increases the benefit of a coup relative to its opportunity cost. It also predicts that coups occur only when the export price, the dictator's investment, and the kingmakers' profits are low (because, in equilibrium, the opportunity cost of a coup increases in these variables).

In electoral competition models of variable leader ability (Banks and Sundaram $\left.^{2}, 1993\right)$ the probability of re-election increases with tenure. The electorate votes out of office leaders of low ability, so that ability is positively related to time in office. By contrast, in our model, the kingmakers seize the opportunity to become dictator whenever it is advantageous, independent of which type is in power. Since periodic shocks affect the efficacy of the dictator's policy, a bad enough shock makes it too costly for even talented dictators to avert a coup. More

\footnotetext{
${ }^{2}$ They are interested in how voters choose election rules to mitigate against the presence of moral hazard and adverse selection.
} 
talented dictators are able to survive more negative shocks, so the worst shock in a dictator's reign is informative about the probability of a coup. We show that, conditional on the worst shock in a dictator's reign, the probability of a coup is independent of a dictator's duration in office but that the unconditional probability of a coup declines with duration. Thus, if one does not control for these "structural" determinants when performing an empirical analysis, a positive correlation between duration and survival probability may appear in the data. We also show that factors other than heterogeneity among dictators may contribute to the observed empirical decline in the hazard rate with duration.

The model draws on previous principal-agent models of both political competition and dictatorship ${ }^{3}$. In these models, the decision-makers instrumental in choosing a new leader are not themselves candidates to be the leader. Thus, in the absence of variable leader ability these decision-makers are indifferent between an old and new leader. In a standard principal-agent model with perfect monitoring, the optimal contract leads the agent to provide an efficient level of investment and the principal never withdraws support for the agent. Thus, in previous models, no leadership turnover occurs in the absence of variable leader ability or in the presence of perfect monitoring. By contrast, we assume that with positive probability subsequent leaders are chosen at random from the finite group of supporters of the current leader. Consequently, coups occur even in the absence of variable leader ability. In addition, support for the leader may be withdrawn under perfect or imperfect monitoring since a coup is now a means of seizing power as well as a punishment. We assume perfect monitoring in order to provide insights into the effect of our assumption in the standard principal-agent model. The predictions of our model remain under imperfect monitoring.

We argue that our results are consistent with the following stylized facts. (1) The risk of leadership turnover in any given year decreases with duration in office

\footnotetext{
${ }^{3}$ Our model draws on the work of Green and Porter (1984), Ferejohn (1986), Olson (1993, 2000), O'Flaherty (1991), and McGuire and Olson (1996). For other principal-agent models of political competition, see Banks and Sundaram (1993). For other dictatorship models, see Wintrobe (1990, 1998), Galetovic and Sanhueza (2000) and Bueno de Mesquita et al. (2001).
} 
(Bienen and van de Walle, 1991). (2) The coup propensity in any given period decreases in real output, measured in either levels or growth rates (Londregan and Poole, 1990; Londregan et al., 1995; Alesina et al., 1996; Galetovic and Sanhueza, 2000). (3) The coup propensity decreases in the export profits of élites (O'Kane, 1987). (4) The coup propensity decreases in real investment, measured in either levels or growth rates (Gallego, 1998). (5) In the presence of an exceptional black market premium, the survival rate decreases in political competitiveness (Bueno de Mesquita et al., 2001). (6) The risk of leadership turnover in African countries increases in the share of the leader's ethnic group (Londregan et al., 1995).

\section{Related Literature}

Though some of these empirical findings may be explained by other models, only our model explains them all.

In the infinite horizon deterministic model of O'Flaherty (1991), a dictator's fortune depends on the support of a core group. Since coups occur only to improve the way in which power is exercised, O'Flaherty finds that, in the absence of uncertainty, the dictator is never ousted. If dictator ability is variable, dictators are either ousted in the first period or rule forever. By contrast, in our model, even the most talented dictator may be ousted as a means for a kingmaker to seize power. Not only is variable ability not necessary for turnover, but also, coups may occur in any period of a dictator's reign.

In a reduced form, one period model of coups, Galetovic and Sanhueza (2000) predict that coups are more likely to follow public unrest and recessions. Because of the reduced form nature of their model, they are unable to provide further predictions. Our model provides microfoundations for the empirical relationship between the coup rate and not only recessions (with no explicit public unrest) but also duration in office and the size of the group of kingmakers.

In an infinite horizon model, Acemoglu and Robinson (2001) study transitions between democratic and non-democratic regimes. We assume, as they do, that the 
élite choose when to stage a coup, that a coup destroys a fraction of the income during the period in which it takes place, and that there is no free rider problem among those who stage a coup. While they model the relationship between the élite and the poor, we model that between the dictator and the élite. Though, in their model, the élite stage coups to transform democracies into dictatorships, and the poor stage revolutions to transform dictatorships into democracies, there is no mechanism for leadership turnover within a regime. By contrast, in our model, the élite stage coups in order to seize the opportunity to become the dictator, and there is no mechanism to switch between dictatorships and democracies.

In the first stage of the two stage electoral competition model of Ferejohn (1986), citizens make a publicly observable choice among performance based voting rules. In the next stage, the leader faces an infinite horizon decision problem. He finds that greater competition among political parties leads to both a greater willingness of the leader to meet voters' demands and a greater voter demand so that no change in turnover need result. By contrast, the agents in our model choose what to do sequentially in each period. We obtain that there is more turnover as competition for the dictator's position increases.

\section{The Model}

Time Time is discrete and continues indefinitely.

Players The number of players is infinite. In each period, one player is the dictator, $n \geq 1$ players are kingmakers, and the remaining players are potential kingmakers. The players' roles may change at the start of a period, depending on the kingmakers' actions and chance. (The mechanism is described below.) At the start of any period in which the identity of the dictator is new, the dictator's type is chosen randomly from the finite set $I$ of numbers; the probability that any type $i$ is chosen is $\pi^{0}(i)$. A dictator's type is known only to the dictator; no kingmaker knows either the dictator's type (though the dictator's action may reveal this type), or the type of dictator they would be. 
We now describe the sequence of events within a period, which is illustrated in Figure 3.1.

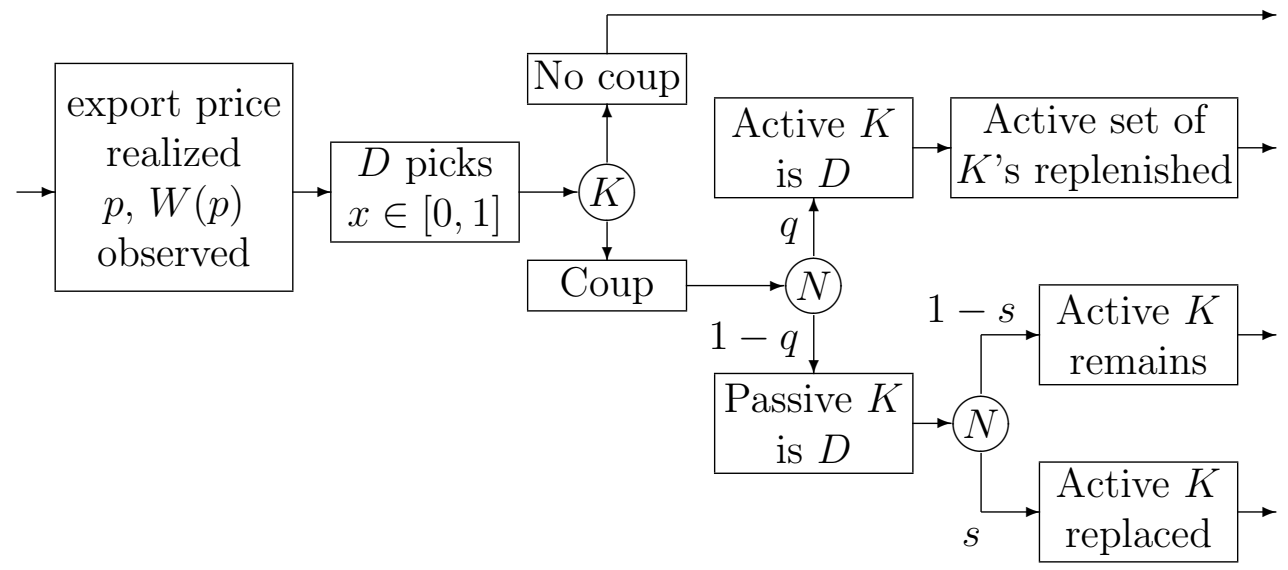

Figure 3.1: Timeline in a period of a dictator's reign. $p$ denotes the export price, $N$, Nature, $D$ the Dictator, and $K$ the Kingmaker.

Beginning of a Period At the start of a period, the players observe a random variable $p$, which we interpret as the price of an export good. This variable is distributed independently and identically each period according to a distribution $F$ with support $[0, \infty)$. After the value $p$ is observed, the dictator receives the rent $W(p)$ (from citizens who have no other role in the model), where $W$ is continuous and $\underline{W} \leq W(p) \leq \bar{W}$ for all $p$.

Dictator's Choice Having received the rent, the dictator makes an investment $x \in[0,1]$ that affects the kingmakers. The kingmakers' payoffs are increasing in $x$, whereas the dictator's payoff is decreasing in $x$. We may interpret $x$ as a policy variable that affects the profits of exporting firms, or simply as a cash transfer.

Kingmakers' Choice After the dictator has chosen an investment, a kingmaker is randomly selected. This "representative" kingmaker decides whether the kingmakers should stage a coup.

Following a Coup If the kingmakers stage a coup, the dictator is ousted. With probability $q \in(0,1]$ the new dictator is a randomly-selected kingmaker, who is replaced by a potential kingmaker. With probability $1-q$ the new dictator 
is a potential kingmaker. In this case we assume that with probability $s$ any given kingmaker interchanges roles with a randomly-selected potential kingmaker and with probability $1-s$ remains kingmaker. That is, with probability $s$ the kingmaker no longer benefits from either a coup or the dictator's investment $x$. The motivation for this assumption is that a kingmaker may not be affiliated with a new dictator. The assumption means whenever a coup occurs, that a kingmaker permanently loses access to power with probability $(1-q) s$. Though there is no free rider problem among the kingmakers (because it is a weakly dominant strategy to take part in a coup whenever the benefit exceeds the opportunity cost, as in Acemoglu and Robinson (2001)), the probabilities $1-q$ and $s$ reflect the fact that coups are risky.

Payoff of Dictator The period payoff to a dictator who chooses $x$ is $W(p)-$ $C_{i}(x)$, where $C_{i}:[0,1] \rightarrow \Re^{+}$is an increasing, convex, continuous function with $C_{i}(0)=0$ and $C_{i}(x)<C_{i+1}(x)$ for all $x \in(0,1], i \in I$. (The cost of providing $x$ is lower for lower types. Our results remain valid if each $C_{i}$ increases in $x / p$ rather than in $x$.) In the absence of a coup, the dictator remains in power. If a coup is staged, the ousted dictator's payoff is zero in every subsequent period. The lifetime payoff of a dictator is the discounted sum of the period payoffs, with discount factor $\delta \in(0,1)$.

Payoffs of Kingmakers In any period in which no coup is staged, each kingmaker receives an equal share $p Y(x) / n$ of export profits, where $p Y(x)$ is the total export profit when the dictator's action is $x$, and $Y:[0,1] \rightarrow \Re^{+}$, is an increasing, concave, continuous function with $Y(0)=0$. In any period in which a coup is staged, each kingmaker's payoff is ${ }^{4} 0$. The lifetime payoff of a kingmaker is the $\delta$ -

\footnotetext{
${ }^{4}$ It seems reasonable to assume (as do Acemoglu and Robinson, 2001) that coups cause economic hardship. All theorems and comparative statics remain valid if the fraction $\phi \in(0,1]$ of profits is lost during a period in which a coup occurs. We can use Lemma A.1 in the Appendix to prove that, in equilibrium, the payoffs increase and the trigger price decreases as $\phi$ increases. For simplicity, we assume that $\phi=1$ so that all period profits are lost. Even if no period profits were lost, i.e., $\phi=0$, then with two-sided uncertainty in the model, arguments similar to those made by Banks and Sundaram (1993) would ensure existence of a MSE with the characteristics of the one we find.
} 
discounted sum of the period payoffs that the kingmaker receives while kingmaker plus the expected payoff that the kingmaker receives if chosen to be dictator after a coup. The period payoff of a potential kingmaker is zero.

Justification for Assumptions Our theory is applicable to leadership turnover in a variety of settings but we cast our model in the framework of a dictator and kingmakers. The consensus is that dictatorial succession is controlled mostly by members of the country's élite (see Luttwak, 1979; Olson 2000; Tullock, 1987; and Wintrobe 1998) so that only a small group of citizens is involved in staging a coup. Luttwak (1979) writes that "Mass participation before and during a coup d'état has been the exception rather than the rule". We abstract from the planning, decision-making and risk-taking of the coup plotter during the staging of the coup. Instead we concentrate on those members of the élite whose cooperation is necessary to stage a coup or maintain a leader in office. We assume that the number of select élites is fixed. ${ }^{5}$

Bueno de Mesquita $^{6}$ et al. (2001) also analyze the relationship between a leader's investment decisions and the existing political institutions. We assume, as they do, that the number of members in the dictator's support group is small relative to the set of feasible members. We assume, as they find, that the investment decision of a dictator is directed toward the dictator's supporters.

In reality, a dictator may also invest in public goods that affect the citizens' well-being and that in turn affect the dictator's rents. By having the rents depend on a stochastic variable (via $W(p)$ ), we want to capture the fact that the tax revenue available to the dictator might vary from period to period. ${ }^{7}$ Thus, the shock may have an effect on the population at large.

In keeping with O'Kane (1987), we assume that both a shock and a leader's investment affect the profits of the élite and that support for a leader may be withdrawn when the response to changes in the shock is deemed inadequate.

\footnotetext{
${ }^{5}$ This assumption seems natural in the case that a country's institutional framework is fixed.

${ }^{6}$ The incumbent is never ousted in the Markov perfect equilibrium that they consider.

${ }^{7}$ See Olson $(1993,2000)$ and McGuire and Olson (1996) for models in which the dictator chooses the tax rate imposed upon the citizens in order to reap the highest tax revenue.
} 
O'Kane finds that countries that are highly dependent on a single good for their export revenue are prone to coups. Export revenue is affected not only by shocks but also by the government response to fluctuations in these shocks. Governments must work hard to maintain support and avoid coups when export revenue is volatile. Though dictators may also use repressive tools to stay in power ${ }^{8}$ we maintain a fixed relationship between the dictator and the citizens.

\section{Equilibrium}

Our model, like other infinite horizon stochastic models, has multiple Nash equilibria ${ }^{9}$. We take the view that only equilibria supported by "credible threats" are compelling, and thus restrict attention to sequential equilibria. In our model, all kingmakers are identical and all dictators of a given type $(i \in I)$ are identical at the beginning of their reign. In addition, the payoffs in each period are determined solely by the current levels of observable variables. We thus further restrict to symmetric Markov sequential equilibria $(\mathrm{MSE})^{10}$. We prove that there is a unique MSE outcome.

We look for a Markov strategy profile in which the state space, decisions sets, period return function, and law of motion are as follows. When a dictator chooses an investment level, the current state being faced consists of the current price, the current beliefs $\pi$ of kingmakers regarding the dictator's type, and the fact of being in office. The decision set of a dictator is the compact set $[0,1]$ of investment levels. A Markov strategy for a dictator of type $i \in I$ transforms prices and beliefs into

\footnotetext{
${ }^{8}$ Wintrobe $(1990,1998)$ explains the changes in repression that occur with changes in economic performance during a dictator's reign. Since the dictator is always willing to purchase some mix of loyalty and repression that maintains the status quo, coups d'état do not occur.

${ }^{9}$ In one Nash equilibrium, kingmakers threaten a coup unless the dictator makes the maximum feasible investment. This threat supports an outcome in which the dictator makes a high investment in each period and a coup is never staged. In one Markov equilibrium the dictator invests zero and kingmakers stage a coup in each period. This equilibrium is supported by kingmakers' strategies that oust the dictator independent of price, investment and beliefs regarding the dictator's type. However, this equilibrium is not sequentially rational.

${ }^{10} \mathrm{~A}$ MSE remains an equilibrium in the game in which players are not restricted to Markov strategies. (See Fudenberg and Tirole, 1992, ch. 13.)
} 
investment levels. The period return function, $W(p)-C_{i}(x)$ for $i \in I$, is bounded and the discount factor $\delta$ is bounded away from 0 and 1 . The law of motion of the system is a conditional probability determined by the Markov strategy of the kingmaker (which stipulates the circumstances of a coup) and so is Markov. Since this dynamic programming problem satisfies Harris (1987, pp. 20-28), the solution is determined by the Bellman equation.

When kingmakers decide on a coup, the current state being faced is the current price, the dictator's current investment, and the current belief they hold regarding the dictator's type. If a coup occurred in the previous period, then the exogenous vector $\pi^{0}$ represents their current belief about the dictator's type. Otherwise, the belief is updated following Bayes' rule whenever possible. The decision set of a kingmaker is the compact set $\{1,0\}$ where 1 indicates a coup and 0 indicates no coup. A Markov strategy transforms the current price, investment and belief into a decision about a coup. The period return function, $p Y(x) / n$, is greater than or equal to zero and the discount factor is bounded away from 0 and 1 . The law of motion of the system is a conditional probability determined by the Markov strategy of the dictator (that stipulates the investment level for each price) and so is Markov. Since this dynamic programming problem satisfies Stokey and Lucas (1989, pp. 241-251), the solution is determined by the Bellman equation.

\subsection{The best response functions}

We now find conditions under which a profile of Markov strategies is a MSE. We begin with the best response function of the representative kingmaker.

When there is a coup, the kingmaker's period payoff is zero so that the benefit of a coup is the discounted present value of either becoming the new dictator or continuing on as kingmaker with a new dictator. The benefit of a coup is therefore independent of the current price and updated beliefs about the previous dictator and depends only on future prices and on the exogenous distribution of dictator types. That is, the benefit of a coup is fixed over time.

When there is no coup, a kingmaker receives a period payment that increases 
in both the dictator's investment and the price. In addition, the kingmakers continue to the next period with no change in dictator. The opportunity cost of a coup is the sum of the current period payoff and the present value of being a kingmaker in the next period while retaining the current dictator. The present value of retaining the current dictator depends on the updated beliefs over dictator types. In general, the opportunity cost depends on the current price, the current investment of the dictator and the current updated beliefs over types. In any feasible MSE strategy of the representative kingmaker, a coup is staged when the variable opportunity cost of a coup is less than the fixed benefit. ${ }^{11}$

What is a dictator's best response to the kingmaker strategies discussed above? The dictator can avert a coup by equating the opportunity cost of a coup to the fixed benefit. Given the current price and beliefs, the opportunity cost of a coup increases in the dictator's investment. However, the lower is $p$, the more costly it is for a dictator to raise the opportunity cost high enough to make a coup unprofitable for the kingmakers. For each type of dictator there exists a sufficiently low $p$ such that it becomes profitable for the dictator to choose $x=0$ and provoke a coup. Only for larger values of $p$, is it profitable for the dictator to avert a coup.

\subsection{Equilibrium}

In any MSE, there are two possibilities in each period: either the dictator equates the opportunity cost of a coup to the benefit and the kingmaker receives the equivalent of the benefit even though no coup is staged; or, the dictator invests zero, a coup is staged, and the kingmaker receives the benefit of a coup. That is, in equilibrium, a kingmaker expects to receive the equivalent of the benefit of a coup as lifetime payment. The benefit of a coup is the discounted present value of either continuing on as kingmaker with a new dictator or becoming the new

\footnotetext{
${ }^{11}$ If the kingmakers stage a coup with positive probability when the opportunity cost of a coup equals the benefit, then, the dictator has no best response. Therefore, in equilibrium, a coup is staged with probability 0 when the opportunity cost equals the benefit.
} 
dictator, i.e., the benefit is

$$
\sigma \delta \mathbf{E} K+\left[\frac{q}{n}\right] \delta \mathbf{E} D_{a}
$$

where $\sigma=1-[q / n]-(1-q) s$ represents the probability of remaining as kingmaker when there is a coup; $\mathbf{E} K$, the lifetime payoff of a kingmaker; $q / n$, the probability of becoming dictator when there is a coup; and $\mathbf{E} D_{a}$, the average lifetime payoff of a newly appointed dictator. Since the kingmaker's expected lifetime payoff in any MSE equals the benefit of a coup we obtain that

$$
\mathbf{E} K=\sigma \delta \mathbf{E} K+\left[\frac{q}{n}\right] \delta \mathbf{E} D_{a} .
$$

After solving for $\mathbf{E} K$, we find that, for any MSE, the benefit of a coup equals

$$
\frac{q}{(1-\sigma \delta) n} \delta \mathbf{E} D_{a} .
$$

In any MSE, the opportunity cost of a coup is the current period payoff plus the present value of being a kingmaker in the next period and so equals

$$
\frac{p Y(x)}{n}+\delta \mathbf{E} K
$$

which depends only on price, investment and exogenous parameters. After substituting for $\mathbf{E} K$ we find that the opportunity cost equals

$$
\frac{p Y(x)}{n}+\frac{q}{(1-\sigma \delta) n} \delta^{2} \mathbf{E} D_{a} .
$$

In equilibrium, the investment that averts a coup equates the opportunity cost in 4.2 to the benefit in 4.1 . That is,

$$
\frac{p Y(x)}{n}=\left[\frac{q(1-\delta)}{(1-\sigma \delta) n}\right] \delta \mathbf{E} D_{a}
$$

so that the equilibrium level of investment required to avert a coup equals

$$
Y^{-1}\left(\frac{q(1-\delta)}{1-\delta \sigma} \times \frac{\delta \mathbf{E} D_{a}}{p}\right)
$$


which depends only on the current price and exogenous parameters.

A dictator of type $i \in I$ equates the opportunity cost of a coup to its benefit only if it is profitable to do so. The coup averting investment increases as price decreases. If the required investment is made, then the dictator incurs a cost and continues on as dictator. The dictator's expected payoff from continuing in power depends only on future prices and exogenous parameters and is thus independent of the current price and updated beliefs. If the dictator chooses not to make the required investment, the dictator invests zero and exits the game. In equilibrium, a dictator of type $i \in I$ makes the required investment only if its cost is less than or equal to the expected payoff of continuing on as dictator, that is

$$
C_{i} \circ Y^{-1}\left(\frac{q(1-\delta)}{1-\delta \sigma} \times \frac{\delta \mathbf{E} D_{a}}{p}\right) \leq \delta \mathbf{E} D_{i}
$$

where $\mathbf{E} D_{i}$ represents the expected payoff of a dictator of type $i$.

\subsection{Trigger Price}

For each type of dictator there is an equilibrium trigger price, below which, prices are sufficiently low that the dictator invests zero and a coup occurs. The equilibrium trigger price equates the cost of the required investment to the dictator's discounted payoff from continuing in power. The equilibrium trigger price equals

$$
P_{i}(\mathbf{E} D)=\frac{q(1-\delta)}{1-\delta \sigma} \times \frac{\delta \mathbf{E} D_{a}}{Y \circ C_{i}^{-1}\left(\delta \mathbf{E} D_{i}\right)}
$$

where $\mathbf{E} D$ represents the vector of payoffs to each type of dictator. At $P_{i}(\mathbf{E} D)$, the dictator is indifferent between equating the opportunity cost of a coup to the benefit and investing 0 and strictly prefers either to any other investment level.

The candidate strategy profiles for MSE can therefore be parametrized by $\mathbf{E} D$, the vector of expected lifetime payoffs to each type of dictator. Associated with any such candidate for MSE, there is a trigger price for each type of dictator such that a coup occurs only for prices below the trigger price of the dictator in power. 


\subsection{Existence and Uniqueness of Equilibrium}

What we have shown is that if the vector $\mathbf{E} D$ represents a MSE then the equilibrium trigger price must satisfy equation 4.3. However, a vector $\mathbf{E} D$ represents a MSE only if the vector is actually consistent with the vector of expected lifetime equilibrium payoffs generated by the associated strategy profile. In fact, though there is a multitude of candidate MSE, we can show that a unique ${ }^{12}$ MSE exists ${ }^{13}$.

Theorem 4.1. There is a unique MSE (up to a set of measure zero).

Unless otherwise stated, all proofs omitted from the text are in the Appendix.

In the basic model, the dictator bribes all kingmakers indirectly by making a costly investment. There is no possibility for the dictator to bribe one of the kingmakers directly by a transfer that convinces a co-opted kingmaker to support the dictator rather than agree to a coup. The repeated nature of the dictator/kingmaker relationship provides the basis for incentives in the model. The dictator and kingmakers are unable to sign binding contracts that determine payments as a function of individual behavior. If we allow the dictator to bribe one of the kingmakers directly by a transfer then, unless the relationship is repeated in the future, each has an incentive to renege on the "agreement". That is, unless the co-opted kingmaker is the representative kingmaker in the period in question and expects future direct transfers, the one time payment does not affect the representative kingmaker's decision. Thus, the availability of bribes does not affect the existence of the unique MSE that we find.

In equilibrium, even the most able dictator may find it too expensive to avert a coup when prices are low enough. Low prices, and not dictator heterogeneity, cause coups in our model. Coups occur even if only one type of dictator exists.

\footnotetext{
${ }^{12}$ If we follow Ferejohn (1986) and assume that information is asymmetric and skewed in favour of the dictator rather than symmetric as in our basic model, then the unique MSE that we find remains an equilibrium.

${ }^{13}$ The dictator's strategy cannot be tied down exactly at the trigger price but in any case, the equilibrium payoffs are independent of what the dictator does when indifferent.
} 


\subsection{The Equilibrium Probability of a Coup}

If a dictator of type $i$ is in power, then a coup occurs only when the price is below the dictator's trigger price. That is, conditional on type $i$, the equilibrium probability of a coup is $F\left(P_{i}\left(\mathbf{E} D^{*}\right)\right)$.

Theorem 4.2. The equilibrium probability of a coup given type $i \in I$ is independent of a dictator's duration in office and increases in $i$.

Since, in any period, the kingmakers may know only a distribution of the dictator's type, the average probability of a coup in the next period is a weighted average of the probabilities of a coup for each type for which the weights are the current updated beliefs concerning dictator types.

If the associated updated distribution depends on the associated price stream as well as the length of time in power, then we refer to the average probability of a coup as the conditional hazard rate. In equilibrium, a dictator averts a coup only when the price is above the trigger price. Since the trigger price increases in a dictator's type, the updated beliefs of the kingmaker depend on one summary statistic of a dictator's reign: the lowest price for which there has been no coup. The lower is this price, the lower is the highest feasible type of dictator, and the more that kingmakers update their beliefs by redistributing weight away from higher types and towards types who are willing to avert a coup at this lower price. It follows immediately that the conditional hazard rate of a coup depends directly on the lowest price in the associated price stream and not specifically on the length of a dictator's term in office. We record this without further proof.

Theorem 4.3. The conditional hazard rate of a coup is independent of a dictator's duration in office.

If the associated updated distribution is conditioned only on the length of time in power and not on the price stream, then we refer to the average probability of a coup as the hazard rate. Since a coup results whenever the export price is below 
a dictator's trigger price, the probability that a dictator of type $j \in I$ survives for $\rho$ periods is $\left(1-F_{j}^{*}\right)^{\rho}$ where $F_{j}^{*}=F\left(P_{j}\left(\mathbf{E} D^{*}\right)\right)$. If we condition only on having survived $\rho$ periods, we can use Bayes' rule to calculate that

$$
\frac{\pi_{i}^{0}\left(1-F_{i}^{*}\right)^{\rho}}{\sum_{j \in I} \pi_{j}^{0}\left(1-F_{j}^{*}\right)^{\rho}}
$$

is the probability that a dictator is of type $i \in I$. The longer a dictator survives, the more biased is the conditional vector of probabilities toward types who face lower costs. We conclude (by Theorem 4.2) that the longer the dictator survives, the lower the probability of a coup next period conditional on time in power.

Theorem 4.4. Suppose that there are at least two types of dictator. An increase in a dictator's duration decreases the hazard rate of a coup.

\section{Comparative Statics}

How do changes in $Y \circ C_{i}^{-1}, n, q$, and $s$ affect the probability of a coup?

Corollary 5.1. If $Y \circ C_{i}^{-1}(x)=\alpha g_{i}(x)$ for $i \in I, \alpha>0$, then the equilibrium probability of a coup falls and all equilibrium payoffs rise as $\alpha$ rises.

Intuitively, for example, as $Y$ shifts up, the opportunity cost of a coup increases relative to the benefit and so the probability of a coup falls.

Corollary 5.2. As the number of kingmakers increases, the equilibrium probability of a coup rises.

Intuitively, as $n$ increases, there is an increase in competition among the kingmakers for the dictator's position and so the probability of a coup increases.

Corollary 5.3. An increase in the probability that a kingmaker loses access to power after a coup implies a decrease in the equilibrium probability of a coup.

Intuitively, the probability of a coup decreases as its benefit decreases. 


\section{Declining Hazard Rate}

We now explore the relationship between the predictions of our model and the stylized facts. Bienen and van de Walle (1991) find that the empirical hazard rate declines with duration in office. We argue here that this observed decline can be explained by various sources of heterogeneity and informational assumptions.

Bienen and van de Walle conjecture that variable innate ability might explain this stylized fact. We formalize this in a model in which a more able dictator faces a lower hazard rate even though, in equilibrium, the kingmakers are indifferent to the ability of the current dictator conditional on initial exogenous beliefs.

Our model shows that, when there is no conditioning on the associated price stream, longer duration in office decreases the hazard rate (Theorem 4.4). We conclude that if the associated extreme shocks are not controlled for in empirical work, the estimated hazard rate should decline with duration.

Our model also predicts that, conditional on the lowest price in the dictator's reign, the conditional hazard rate of a coup is independent of duration in office (Theorem 4.3). This result points the way to a proxy for dictator ability that could be used in empirical studies as a variable that accounts for differences in hazard rates. Our model interprets an exogenous i.i.d. shock that affects kingmakers' profits as an export price. While it may be difficult to measure a dictator's ability directly, one may be able to identify a stream of aggregate i.i.d. shocks (for example, the stream might be periodic measurements of export demand, production or price) that affect kingmakers' profits and so is informative about the dictator's ability. If these informative extreme exogenous shocks are included as variables that explain the hazard rate, then this should diminish the empirically observed decline in the hazard rate as duration increases.

Corollaries 5.2 and 5.3 also suggest variables that might be used to explain the empirical decline in the hazard rate with duration. Differences among kingmaker group size and among the exit rate of kingmakers are each associated with differences in the hazard rate. Our model suggests that if measures or proxies 
for $n, q$, and $s$ are included in cross country empirical studies as variables that explain the hazard rate, this may also diminish the observed decline in the hazard rate with duration. That is, the empirically declining hazard may be explained by several heretofore unmeasured sources of heterogeneity across dictators and countries. We now examine whether our predictions relating the hazard rate to other parameters of the model are consistent with the stylized facts.

\section{Low Output/Investment and High Probability of a Coup}

A high coup propensity is associated empirically with a decrease in GDP, investment (INV) or EXPORTS ${ }^{14}$. The evidence on GDP is as follows. Per capita lagged GDP is used by Londregan and Poole, 1990, in a worldwide sample, and by Londregan et al., 1995, in a sample of African countries; current growth rate is used by Alesina et al., 1996, in a worldwide sample; per capita current GDP is used by Galetovic and Sanhueza, 2000, in a sample of developing countries with autocratic regimes. The evidence on EXPORTS links coups to a decline in the export profits of élites in a multi-country analysis (O'Kane, 1987). The evidence on INV uses either current or (one period) lagged per capita levels or growth (Gallego, 1998, in a worldwide sample of leaders who exit unconstitutionally).

Broadly speaking, we predict that the probability of a coup decreases in (i) the shock affecting kingmaker profits, (ii) the services provided by the dictator for the kingmaker, (iii) the well-being of kingmakers, and (iv) shifts in kingmaker production functions. While we know of no empirical studies which measure any of these variables directly, we argue below that each variable might be correlated with INV, EXPORTS, and GDP (measured in levels or growth rates).

In reality, the dictator may provide services to the citizens that affect the rents accruing to the dictator each period ${ }^{15}$. For simplicity and tractability, we assume that while the services provided for citizens are fixed, the dictator chooses how

\footnotetext{
${ }^{14}$ The data consists of annual information on EXPORTS, INV, GDP, and exit dates.

${ }^{15}$ See Olson $(1993,2000)$ and McGuire and Olson (1996) for models in which the dictator invests only in a pure public good for the citizens.
} 
much to provide of a service that is targeted to the kingmakers and does not affect the rents. If we interpret $x$ more broadly to mean any service that the dictator provides for the kingmakers, then we can find proxies for " $x$ " in the literature. Bueno de Mesquita et al. (2001), Olson (2000), and Wintrobe (1998) discuss a variety of "public" services that dictators provide to their supporters. The services include, but are not limited to, preferential access to (i) high quality goods, (ii) lucrative contracts, (iii) education subsidies (iv) limited foreign exchange in countries with high black market premiums, and (v) favourable labour and trade policies. Services might also take the form of maintaining public order.

If we accept that kingmakers are the economic élites in less developed countries (LDC's), then, given that the services provided by public infrastructure mostly benefit these élite ${ }^{16}$, investment in public infrastructure or its maintenance may be used as a proxy for the provision of services directed toward the élite. In this case, ceteris paribus, the smaller the provision of service, the smaller is public investment or public expenditure ${ }^{17}$. Depending on how dictators deliver these services, our model could be supported by an empirical finding that the probability of a coup decreases in public investment or public expenditure.

If we accept that per capita private real investment is an indicator of the wellbeing of the élites ${ }^{18}$ then private investment can also be a proxy for kingmaker payoffs. That is, a low level of kingmaker payoffs is associated with a low level of private investment. Previously, we have shown that depending on which services are provided to the kingmakers, the probability of a coup may decrease in public investment. Since public and private investment are complements (Green and Villanueva, 1991), our model is supported broadly by the empirical finding that the probability of a coup decreases in aggregate investment, INV.

Though kingmakers may have sources of income that do not depend on the

\footnotetext{
${ }^{16}$ See Table 1.4, page 32 of the World Development Report (1994).

${ }^{17}$ The data in LDC's may not distinguish between government investment and expenditure.

${ }^{18}$ Since the élite of LDC's have preferential access to domestic investment opportunities and have the means to invest, it is reasonable to assume that the élites contribute to the bulk of private investment in LDC's.
} 
dictator's actions, these sources are fixed in the model. However, exports are a source of income that is affected by the dictator's trade policy. In addition, a shift in $Y$ is associated theoretically with an increase in kingmaker earnings (through their share in the export firms) and a decrease in the probability of a coup (Corollary 5.1). If we accept that the élites in LDC's own the bulk of export firms then EXPORTS is also a measure of the well-being of kingmakers. In addition, if we accept that income is highly concentrated among the élites in LDC's ${ }^{19}$ and that the income of the élite fluctuates with the level of service provided by the dictator, then GDP may also be a proxy for kingmaker payoffs. This implies a negative correlation between the probability of a coup and both EXPORTS and GDP. Our model is supported broadly by the empirical finding that the probability of a coup decreases in EXPORTS and GDP.

Lastly, the endogenous growth literature decomposes growth into components associated with changes in capital, labour, or increases in productivity. The function $Y \circ C_{i}^{-1}$ represents the production of goods. ${ }^{20}$ In our model, $Y$ and $C_{i}$ depend directly only on the level of public investment that is targeted to the kingmakers. However, any change in labour, capital, or technology represents a shift in $Y \circ C_{i}^{-1}$. An upward shift in $Y \circ C_{i}^{-1}$ can be associated with higher levels of GDP and GDP growth since each can be affected by, say, an increase in education ${ }^{21}$. Corollary 5.1 implies that an increase in GDP (occasioned by, say, an increase in education) can be associated with a decrease in the probability of a coup.

We conclude that our model is supported broadly by the findings that the probability of a coup decreases in INV, EXPORTS, and GDP.

\footnotetext{
${ }^{19}$ See Table 30 on page 220 of the World Development Report (1994).

${ }^{20}$ The cost of producing $\mu$ units of private good using $Y^{-1}(\mu)$ units of public investment provided by the dictator is $C \circ Y^{-1}(\mu)$ so that its inverse $Y \circ C^{-1}$ is the production function.

${ }^{21}$ Spending on higher education mainly benefits the élite in LDC's. (See Alesina, 1998).
} 


\section{Large Coalition and High Hazard Rate}

We find that an increase in the hazard rate follows either a decrease in $s$ or an increase in $n$ or $q$ (Corollaries 5.1, 5.2 and 5.3). There are two pieces of evidence that suggest these results. Empirical evidence is presented in Table 1 of Bueno de Mesquita et al. (2001) that an increase in the size of a leader's winning coalition decreases the survival rate among leaders who target their policies to benefit those in their winning coalition. Our kingmakers are comparable to the members of the winning coalition in their paper. In addition, the policies that we consider (an excludable public good targeted exclusively to the set of kingmakers) are comparable to those that benefit members of the winning coalition (a black market premium) in their paper. Thus, the evidence supports our prediction that as the size of the group of kingmakers increases, the hazard rate of a dictator increases.

In Londregan et al. (1995), there is evidence that relates the probability of an unconstitutional exit in African countries to the population share of the leader's ethnic group. They create an ethnicity index that measures the share of the leader's group and that takes into account the degree of diffusion among the country's ethnic groups. They find that, after controlling for relevant economic and political factors (so that in the context of our model $W, C, Y, F$, and $p$ are held constant while $n, q$, and $s$ are free to vary), as the index increases beyond 0.57 , the conditional probability of a non-constitutional exit increases.

We claim that an increase in the ethnicity index beyond 0.57 (while holding the population and the number of its ethnic groups constant) can be interpreted as an increase in $n$ and/or $q$, and/or a decrease in $s$. When the current leader's ethnic group is large, evidence suggests that the élites of the current leader's ethnic group benefit when any largesse is extended by the leader and suffer losses when the leader decides to withdraw favours. ${ }^{22}$ Evidence also suggests "an ethnic incumbency advantage" since the probability that a new dictator comes from the

\footnotetext{
${ }^{22}$ African politicians rule through personal patronage (Bratton and van de Walle, 1994).
} 
current leader's ethnic group increases in the size of the leader's ethnic group ${ }^{23}$. Intuition is supplied by Londregan et al. (1995) who postulate that, as the size of a leader's ethnic group grows, the allegiance to any particular leader weakens as the group is confident of appointing the leader's successor and thereby remaining as direct beneficiaries. We conclude that, in Africa, the group of élites of the current leader's ethnic group benefits from the dictator's investment. In addition, when large, not only does the group decide whether to stage a coup but also each of its members has some chance of becoming the new dictator. Thus, the élites of a leader's large ethnic group meet our model's criteria of kingmakers.

Since the size of the leader's support group of élites is positively correlated with the size of the leader's ethnic group ${ }^{24}$ and with the probability that the ethnic group both supplies the new leader and remains the beneficiary of a new leader's largesse, the empirical evidence supports the model's prediction that leadership turnover increases as $n$ or $q$ increases or as $s$ decreases.

\section{Conclusion}

The innovation in our model is our assumption that leadership turnover may confer a direct benefit on a random member of the group of kingmakers. As a result, the demand for coups derives from the kingmaker's desire to seize power rather than the quest for a low cost dictator. In consequence, leadership turnover may occur in any period despite the fact that the kingmakers are indifferent among dictator types (given a fixed distribution of types). The equilibrium that we find remains in the presence of imperfect monitoring and the availability of bribes.

Our model explains the six above-mentioned stylized facts on coups and offers new variables that may influence the probability of a coup. For example, the

\footnotetext{
${ }^{23}$ Londregan et al. (1995) find that any immediate successor is disproportionately more likely to emerge from within the ethnic group of the current leader.

${ }^{24}$ Suppose that the population and the number of ethnic groups remains fixed. Consider a redistribution of the population into ethnic groups such that the population share and therefore size of the leader's ethnic group increases. In this case, it is reasonable to assume that the size of the group of élites within the leader's ethnic group increases with the size of the ethnic group.
} 
model explains that having weathered very negative shocks with no ill effects bodes well for the staying power of the current dictator. The model also expands the influence of the group of kingmakers beyond that of their decisions regarding the staging of coups. Both the size of the group and the risk of involuntarily exiting from this group have a role in determining the probability of a coup.

\section{A. Appendix}

Proof. (THEOREM 4.1): We know that each trigger price must be strictly positive since, for each $i \in I$, each equilibrium payoff $\mathbf{E} D_{i}$ lies in the compact, convex set $[\underline{W}, \bar{W} /(1-\delta)]$. The strategy profile associated with the payoff vector $\mathbf{E} D$ is a MSE if and only if $\mathbf{E} D_{i}$ solves the simultaneous system of equations

$$
\begin{aligned}
& \mathbf{E} D_{i}=\mathbf{E} W+\delta \mathbf{E} D_{i}\left[1-F\left(P_{i}(\mathbf{E} D)\right)\right] \\
& -\quad \int_{P_{i}(\mathbf{E} D)}^{\infty} C_{i} \circ Y^{-1}\left(\frac{q(1-\delta)}{1-\delta \sigma} \times \frac{\delta \mathbf{E} D_{a}}{p}\right) d F(p) \quad \text { for } i \in I .
\end{aligned}
$$

A solution to A.1 exists by Brouwer's fixed point theorem.

Let the RHS of A.1 be denoted by $h_{i}(\mathbf{E} D)$ for $i \in I$. We take derivatives to calculate the differentials of $h_{i}$ to approximate the changes in $h_{i}$ for small changes in $\mathbf{E} D_{j}$ for $j \in I$. The approximations then show that the solution is unique.

The derivative of $\mathbf{E} D_{i}$ w.r.t. $\mathbf{E} D_{i}$ is 1 . Since $\sigma=1-[q / n]-(1-q) s \leq 1$ and $q(1-\delta)+\delta \sigma<q(1-\delta)+\delta<1$, we obtain that

$$
\bar{\kappa}=\frac{q(1-\delta)}{1-\delta \sigma} \in(0,1) .
$$

The derivative of $h_{i}$ w.r.t. $\mathbf{E} D_{i}$ can be simplified to yield

$$
\delta\left[1-F\left(P_{i}(\mathbf{E} D)\right)\right]-\pi_{i}^{0} \delta \int_{P_{i}(\mathbf{E} D)}^{\infty}\left\{\frac{\bar{\kappa}}{p} \cdot\left(C_{i} \circ Y^{-1}\right)^{\prime}\left(\frac{\bar{\kappa} \delta \mathbf{E} D_{a}}{p}\right)\right\} d F(p)
$$

The derivative of $\mathbf{E} D_{i}$ w.r.t. $\mathbf{E} D_{j}(j \neq i)$ is zero while that of the integral component of $h_{i}$ is

$$
-\pi_{j}^{0} \delta \int_{P_{i}(\mathbf{E} D)}^{\infty}\left\{\frac{\bar{\kappa}}{p} \cdot\left(C_{i} \circ Y^{-1}\right)^{\prime}\left(\frac{\bar{\kappa} \delta \mathbf{E} D_{a}}{p}\right)\right\} d F(p)
$$


so that $\partial h_{i}(\mathbf{E} D) / \partial \mathbf{E} D_{j}<0(j \neq i)$ since $\left(C_{i} \circ Y^{-1}\right)^{\prime}$ is positive.

Suppose that $z^{0} \in[\underline{W}, \bar{W} /(1-\delta)]^{\operatorname{cardinality}(I)}$. As we change $z_{i}^{0}$ to $z_{i}^{0}+\Delta_{i}$ for $i \in I$, the LHS of equation $i$ changes to $z_{i}^{0}+\Delta_{i}$. Let $\Delta_{a}=\sum_{i \in I} \pi_{i}^{0} \Delta_{i}$ and let $z_{a}^{0}=\sum_{i \in I} \pi_{i}^{0} z_{i}^{0}$. When $\Delta_{i}=d z_{i}, i \in I$, are small the differential

$$
d h_{i}=\frac{\partial h_{i}}{\partial z_{i}} d z_{i}+\sum_{j \neq i, j \in I} \frac{\partial h_{i}}{\partial z_{j}} d z_{j}
$$

approximates the change in $h_{i}$. If we use equations A.2 and A.3 to approximate the effect of these changes on $h_{i}, i \in I$, then we obtain that.

$$
\begin{aligned}
d h_{i} & =\delta\left[1-F\left(P_{i}\left(z^{0}\right)\right)\right] \Delta_{i} \\
& -\delta\left[\int_{P_{i}\left(z^{0}\right)}^{\infty} \frac{\bar{\kappa}}{p}\left(C_{i} \circ Y^{-1}\right)^{\prime}\left(\frac{\bar{\kappa} \delta z_{a}^{0}}{p}\right) d F(p)\right]\left[\Delta_{a}\right]
\end{aligned}
$$

Partition the set of types so that $I_{1} \cup I_{2} \cup I_{3}=I$ where $\Delta_{j}>\Delta_{k}=0>\Delta_{l}$ for $j \in I_{1}, k \in I_{2}, l \in I_{3}, I_{1} \cup I_{3} \neq \emptyset$. We show that there exists at least one type $i$ for which $d h_{i} \neq \Delta_{i}$. Suppose $\Delta_{a}>0$ so that $I_{1} \neq \emptyset$. In this case, $d h_{i}<\Delta_{i}$ for all $i \in I_{1}$. Suppose that $\Delta_{a}<0$ so that $I_{3} \neq \emptyset$. In this case, $d h_{i}>\Delta_{i}$ for all $i \in I_{3}$.

If $z^{0}$ solves system A.1 then any change in $z^{0}$ associated with $\Delta_{a}>0\left(\Delta_{a}<0\right)$ and partition $I=I_{1} \cup I_{2} \cup I_{3}$ can be achieved by incremental changes each of which is associated with $\Delta_{a}>0\left(\Delta_{a}<0\right)$ and partition $I=I_{1} \cup I_{2} \cup I_{3}$. Since, for each incremental change, the estimated change in $h_{i}$ is less than (more than) the actual change in $z_{i}$ for $i \in I_{1}$, the estimated total change $d h_{i}$ must be less than (more than) the actual change $\Delta_{i}$ for $i \in I_{1}$. Thus, the fixed point is unique.

Proof. (THEOREM 4.2): It is immediate that $F\left(P_{i}\left(\mathbf{E} D^{*}\right)\right)$ is independent of duration. The fact that $C_{i}(x)<C_{i+1}(x)$ and that $C_{i}$, is increasing in $x \in(0,1]$ for $i \in I$, implies that $\left(C_{i+1}\right)^{-1}\left(\delta \mathbf{E} D_{i+1}^{*}\right)<\left(C_{i}\right)^{-1}\left(\delta \mathbf{E} D_{i}^{*}\right)$ so that (by equation 4.3) $F\left(P_{i}\left(\mathbf{E} D^{*}\right)\right)<F\left(P_{i+1}\left(\mathbf{E} D^{*}\right)\right)$ as required.

Proof. (THEOREM 4.4): If $F_{k}^{*}=F\left(P_{k}\left(\mathbf{E} D^{*}\right)\right.$ ) for any $k$, then, conditional on surviving for $\rho$ periods, the probability that a dictator is of type $i \in I$ is

$$
\pi_{i}(\rho)=\frac{\pi_{i}^{0}\left(1-F_{i}^{*}\right)^{\rho}}{\sum_{j \in I} \pi_{j}^{0}\left(1-F_{j}^{*}\right)^{\rho}} .
$$


Since both share a common positive denominator, Theorem 4.2 implies that the derivative, $\pi_{i}^{\prime}(\rho)$, is greater than $\pi_{i+1}^{\prime}(\rho)$ since

$$
\sum_{j \in I} \pi_{j}^{0}\left(1-F_{j}^{*}\right) \ln \left(\frac{1-F_{i}^{*}}{1-F_{i+1}^{*}}\right)>0
$$

Another application of Theorem 4.2 implies the result.

Proof. (COROLLARY 5.1): Recall that $Y \circ C_{i}^{-1}=\alpha g_{i}$ for $i \in I$ and let

$$
G_{i}(\alpha)=\frac{\bar{\kappa} \delta z_{a}^{*}(\alpha)}{\alpha g_{i}\left(s \delta z_{i}^{*}(\alpha)\right)}
$$

be the equilibrium trigger price of dictator $i \in I$ where $z^{*}(\alpha)=\mathbf{E} D^{*}(\alpha)$.

We first show that $z_{i}^{\prime}(\alpha)>0$. Note that while the LHS of each equation in A.1 remains constant, the RHS shifts up as $\alpha$ increases. Thus, if $\alpha$ increases from $\alpha^{1}$ to $\alpha^{2}$ then to obtain a new solution $z^{0}\left(\alpha^{2}\right)$, we move incrementally to the "northeast" of the old solution $z^{0}\left(\alpha^{1}\right)$ (where $\alpha^{1}<\alpha^{2}$ ) in such a way that the changes $\Delta_{i}$ in $z_{i}$ are such that $\Delta_{a}>0, \Delta_{i}>0$ for $i \in I$, and $\Delta_{a}=\sum_{i \in I} \pi_{i}^{0} \Delta_{i}>0$ which imply that $d f_{i}<\Delta_{i}$ for $i \in I$ (see the proof of Theorem 4.1) so that the RHS of equation $i$ in A.1 increases by less than the LHS. That is, $z_{i}^{\prime}(\alpha)>0$. The kingmaker's payoff in formula 4.1 enables us to conclude that the kingmaker's payoff also increases in $\alpha$.

The derivative $G_{i}^{\prime}(\alpha)<0$ if and only if

$$
\frac{\alpha z_{a}{ }^{\prime}(\alpha)}{z_{a}(\alpha)}<\frac{g_{i}\left(\delta z_{i}^{*}(\alpha)\right)+\alpha s \delta z_{i}^{*^{\prime}}(\alpha) g_{i}^{\prime}\left(\delta z_{i}^{*}(\alpha)\right)}{g_{i}\left(\delta z_{i}^{*}(\alpha)\right)}
$$

The RHS of inequality A.4 is greater than or equal to one since $\alpha>0, s \geq 0$, $\delta>0, g^{\prime}>0$ and $z_{i}^{\prime}(\alpha)>0$. That $G^{\prime}(\alpha)<0$ follows if the LHS of inequality A.4 is less than one. We know from equation A.1 that

$$
\begin{aligned}
& z_{i}^{* \prime}(\alpha)\left\{1-\delta\left[1-F\left(G_{i}(\alpha)\right)\right]\right\}+\frac{\bar{\kappa} \delta z_{a}^{* \prime}(\alpha)}{\alpha} \int_{G_{i}(\alpha)}^{\infty} \frac{1}{p}\left(g_{i}^{-1}\right)^{\prime}\left(\frac{\bar{\kappa} \delta z_{a}^{*}(\alpha)}{p \alpha}\right) d F(p) \\
& =\frac{\bar{\kappa} \delta z_{a}^{*}(\alpha)}{\alpha^{2}} \int_{G_{i}(\alpha)}^{\infty} \frac{1}{p}\left(g_{i}^{-1}\right)^{\prime}\left(\frac{\bar{\kappa} \delta z_{a}^{*}(\alpha)}{p \alpha}\right) d F(p)
\end{aligned}
$$


for $i \in I$. If we then let $A z_{a}^{* \prime}(\alpha)=\sum_{i \in I} \pi_{i}^{0} z_{i}^{* \prime}(\alpha)\left\{1-\delta\left[1-F\left(G_{i}(\alpha)\right)\right]\right\}$ where $A \in(0,1)$ we can compute the average of the above equalities and then multiply by $\alpha / z_{a}^{*}(\alpha)$ to obtain that

$$
\frac{\alpha z_{a}^{* \prime}(\alpha)}{z_{a}^{*}(\alpha)}=\frac{\frac{\bar{\kappa} \delta}{\alpha} \sum_{i \in I} \pi_{i}^{0} \int_{G_{i}(\alpha)}^{\infty} \frac{1}{p}\left(g_{i}^{-1}\right)^{\prime}\left(\frac{\bar{\kappa} \delta z_{a}^{*}(\alpha)}{p \alpha}\right) d F(p)}{A+\frac{\bar{\kappa} \delta}{\alpha} \sum_{i \in I} \pi_{i}^{0} \int_{G_{i}(\alpha)}^{\infty} \frac{1}{p}\left(g_{i}^{-1}\right)^{\prime}\left(\frac{\bar{\kappa} \delta z_{a}^{*}(\alpha)}{p \alpha}\right) d F(p)}
$$

which is less than one since $A>0$ and so proves the result.

Lemma A.1. If the coup averting investment is $Y^{-1}\left(\kappa(\tau) \delta z_{a}(\tau) / p\right)$ and

$$
\Gamma_{i}(\tau)=\kappa(\tau) \times \frac{\delta z_{a}^{*}(\tau)}{g_{i}\left(\delta z_{i}^{*}(\tau)\right)}
$$

is the equilibrium trigger price for $i \in I$, where $z^{*}(\tau)=\mathbf{E} D^{*}(\tau), g_{i}=Y \circ C_{i}^{-1}$, and $\kappa(\tau) \in(0,1)$. The sign of $\Gamma_{i}^{\prime}(\tau)$ equals the sign of $\kappa^{\prime}(\tau)$.

Proof. If both $g_{i}$ and $g_{i}^{\prime}$ are evaluated at $\delta z_{i}^{*}(\tau)$ for $i \in I$ then

$$
\Gamma_{i}^{\prime}(\tau)=\frac{\kappa^{\prime}(\tau) \delta z_{a}^{*}(\tau)}{g_{i}}+\frac{\kappa(\tau) \delta z_{a}^{* \prime}(\tau)}{g_{i}}-\frac{\kappa(\tau) \delta z_{a}^{*}(\tau) \delta z_{i}^{* \prime}(\tau) g_{i}^{\prime}}{g_{i}^{2}}
$$

Equation A.1 implies that

$$
z_{i}^{* \prime}(\tau)=-\left[\kappa^{\prime}(\tau) \delta z_{a}^{*}(\tau)+\kappa(\tau) \delta z_{a}^{* \prime}(\tau)\right] B_{i}(\tau)
$$

for $i \in I$ where

$$
B_{i}(\tau)=\frac{\int_{\Gamma_{i}(\tau)}^{\infty} \frac{1}{p}\left(g_{i}^{-1}\right)^{\prime}\left(\frac{\kappa(\tau) \delta z_{a}^{*}(\tau)}{p}\right) d F(p)}{1-\delta\left[1-F\left(\Gamma_{i}(\tau)\right)\right]} \in(0, \infty)
$$

We can compute the average of the equalities in A.6 to obtain

$$
z_{a}^{* \prime}(\tau)=-\frac{\kappa^{\prime}(\tau) \delta z_{a}^{*}(\tau) B(\tau)}{1+\delta \kappa(\tau) B(\tau)}
$$

where $B(\tau)=\sum_{i \in I} \pi_{i} B_{i}(\tau)$. If we then substitute in equalities A.6 we obtain

$$
z_{i}^{* \prime}(\tau)=-\kappa^{\prime}(\tau) \delta z_{a}^{*}(\tau) B_{i}(\tau)\left[\frac{1}{1+\kappa(\tau) \delta B(\tau)}\right]
$$


for $i \in I$. If we substitute for $z_{i}^{* \prime}(\tau)$ and $z_{a}^{* \prime}(\tau)$ for $i \in I$ in equation A.5 and if we let $H(\tau)=1 /[1+\delta \kappa(\tau) B(\tau)]$ we find that

$$
\Gamma_{i}^{\prime}(\tau)=\kappa^{\prime}(\tau) \times \frac{\delta z_{a}^{*}(\tau)}{g_{i}} \times H(\tau) \times\left[1+\frac{\delta \kappa(\tau) \delta z_{a}^{*}(\tau) B_{i}(\tau) g_{i}^{\prime}}{g_{i}}\right]
$$

for $i \in I$. Since $z_{a}^{*}(\tau)>0, g_{i}>0, g_{i}^{\prime}>0, B_{i}(\tau)>0$ and $H(\tau)>0$, it follows that the sign of $\Gamma_{i}^{\prime}(\tau)$ equals that of $\kappa^{\prime}(\tau)$ for $i \in I$ as required.

Proof. (COROLLARIES 5.2 and 5.3): This follows from Lemma A.1 since $\kappa=q(1-\delta) /[1-\delta\{1-[q / n]-q s\}]$ increases in $q$ and decreases in $s$.

\section{References}

[1] Acemoglu, D., Robinson, J.A., 2001, A Theory of Political Transitions, American Economic Review, 91(4), 938-64.

[2] Alesina, A., Özler, S., Roubini, N., Swagel P., 1996, Political Instability and Economic Growth, Journal of Economic Growth, 1(2), 189-211.

[3] Alesina, A., 1998, The Political Economy of Macroeconomic Stabilizations and Income Inequality: Myths and Reality, In: Tanzi and Chu, eds., Income Distribution and High-Quality Growth, 299-326.

[4] Banks, J., Sundaram, R.K.,1993, Adverse selection and Moral Hazard in a Repeated Elections Model. In: Barrett, Hinich, and Schofield, eds., Political Economy: Institutions, Competition and Representation, Cambridge University Press.

[5] Bienen, H., van de Walle, N., 1991, Of Time and Power: Leadership Duration in the Modern World, Stanford University Press, Stanford, California.

[6] Blondel, J. 1980, World Leaders: Heads of Government in the Postwar Period, Sage Publications, London and Beverly Hills. 
[7] Bratton, M., van de Walle, N., 1994, Neopatrimonial Regimes and Political Transitions in Africa, World Politics, 46, 453-89.

[8] Bueno de Mesquita, B., Morrow, J. D., Siverson, R., Smith, A., 2001, Political Incentives and Political Institutions: When Bad Policy is Good Politics. In: paper presented to conference on Preferences, Choice and Uncertainty: Analyzing Choice in Political and Social Settings at UC - Davis, May.

[9] Ferejohn, J., 1986, Incumbent Performance and Electoral Competition, Public Choice, 50, 5-25.

[10] Fudenberg, D., Tirole, J., 1992, Game Theory, MIT Press.

[11] Galetovic, A., Sanhueza, R., 2000, Citizens, Autocrats, and Plotters: A Model and New Evidence on Coups D'État, Economics and Politics, 12(2), $183-204$.

[12] Gallego M., 1998, Economic Performance and Leadership Accountability: An Econometric Analysis, Economics and Politics, 10(3), 249-296.

[13] Green, E., Porter, R. H., 1984, Noncooperative Collusion Under Imperfect Information, Econometrica, 52(1), 87-100.

[14] Greene, J., Villanueva, D., 1991, Private Investment in Developing Countries: An Empirical Analysis, I-M-F-Staff-Papers, 38, 33-58.

[15] Harris, M., 1987, Dynamic Economic Analysis, Oxford University Press.

[16] Londregan, J. B., Bienen, H., van de Walle, N., 1995, Ethnicity and Leadership Succession in Africa, International Quarterly Studies, 39, 1-25.

[17] Londregan, J. B., Poole, K. T., 1990, Poverty, the Coup Trap, and the Seizure of Executive Power, World Politics, 42(2), 151-183.

[18] Luttwak, E., 1979, Coup d'état: A Practical Handbook, Cambridge, Massachusetts, Harvard University Press. 
[19] McGuire, M. C., Olson, M., 1996, The Economics of Autocracy and Majority Rule: The Invisible Hand and the Use of Force, Journal of Economic Literature, 34, 72-96.

[20] O'Flaherty, B., 1991, How to be a Dictator: The Advantages of Incumbency, Columbia University, Department of Economics WP 530.

[21] O'Kane, R. H. T., 1987, The Likelihood of Coups, Averbury.

[22] Olson, M., 1993, Dictatorship, Democracy, and Development, American Political Science Review, 87(3), 567-76.

[23] Olson, M., 2000, Power and Prosperity; Outgoing Communist and Capitalist Dictatorships, Basic Books.

[24] Stokey N. L., Lucas, R. E., 1989, Recursive Methods in Economics Dynamics, Harvard University Press.

[25] Sanhueza, R. (1999) "The Hazard Rate of Political Regimes", Public Choice, 98: $337-367$.

[26] Sutter, D. (2000) "A Game Theoretic Model of Coup D'État," Economic and Politics, 12(2):205-223.

[27] Tullock, G., 1987, Autocracy, Kluwer Academic Publishers.

[28] Wintrobe, R., 1990, The Tinpot and the Totalitarian: An Economic Theory of Dictatorship, American Political Science Review, 84 (3), 849-872.

[29] Wintrobe, R., 1998, The Political Economy of Dictatorship, Cambridge University Press.

[30] World Development Report, 1994, Infrastructure for Development. 